\title{
A CASE OF SYNESTHESIA
}

BY ISADOR H. CORIAT, M.D., BOSTON, MASS.

YASES of synesthesia are sufficiently rare to warrant the recording and analysis of any new observations. In the case which I wish to report, the various synesthesias encountered (colored hearing and thinking, taste synesthesia) while limited in their scope yet were quite intense. The subject was an intelligent woman, forty-one years of age, of a decided visual type. For a number of years she had suffered from a typical anxiety neurosis (without hysterical stigmata or limitation of the field of vision) which had recently been cured through psycho-analysis. After she had recovered from her psychoneurotic symptoms, she mentioned her synesthesias for the first time, whereupon a study of the condition was undertaken. The synesthesia antedated by years the development of the anxiety neurosis, in fact, it could be traced back to the earliest years of childhood. Physically the subject was in perfect condition. There was no psychopathic or neuropathic heredity and no similar synesthetic disorder existing in any member of the family. She does not remember the time when she did not have the colored hearing and thinking.

In this subject the synesthesia was rather rudimentary and limited in its scope, in that only one color, blue, in its various shades was distinctly suggested by sounds. The shade of the color varied according to the sounds or thought. She remembered that once, when very young, she was given a doll dressed in blue. She immediately named her "Lucy Blue," while to her sister's doll, which was dressed in red, she gave the name of "Lucy Red." Her sister could not seem to comprehend this linking of a color with a name. Pieces of colored glass delighted her, while a kaleidoscope always produced a feeling of great satisfaction. Red sunsets were depressing, to use the subjects expression, "they were so beautiful that they hurt."

Certain sounds were blue and the principal words associated with the colored hearing were as follows:

"Nellie" - pale blue, an umlimited sky blue (spatial sense). 
"Lucy"- a clear sapphire.

"Bertha" - a deep Prussian blue."

Sometimes "Nellie" is described as "pale, soft blue, but very clear."

Further analysis demonstrated, that the predominating color of these three words was produced by the color of a combined vowel and consonant within the word. For instance, in "Lucy," the sound "loo" caused the color; in "Nellie," "el" produced the predominating color effect, while in "Bertha" the letters "er" colored the word. "L" alone without the vowel, or " $\mathrm{R}$ " alone, did not produce a blue sensation. It seemed, therefore, that the vowel sounds were the instigators of the synesthesia, although why the letter " $E$ " produced a pale blue color in one case and a Prussian blue in the other, could not be determined. Strangely enough, the French words "Berthe," "Allemand" and "berceau," although containing the same vowel combinations, produce no color sensation, although "Berthe" appeared "higher" (to use the subject's description) than "Bertha." Unlike other reported cases, therefore, particularly the one studied by Marinesco, the synesthesia was limited to the phonetic combinations of one language, in this case, English.

Conversely, showing the subject a blue or red disc, such as those used for taking the field of vision, produced no association with a word or sound. Tests with a tuning fork and watch demonstrated hearing to be normal. A (long) is not colored, but sounds "cool." The long vowels suggested positions on a chromatic scale, rather than color, but these positions were not very clear to her. For instance:

$$
\begin{aligned}
& \overline{\mathrm{a}}=\text { do. } \\
& \overline{\mathrm{e}}=\text { re. } \\
& \overline{\mathrm{i}}=\text { do (second octave) } .
\end{aligned}
$$

The vowel sounds also produced other sensations, as follows:

$$
\begin{aligned}
& \bar{a}=\text { cool sound. } \\
& \bar{a}=\text { no sound. } \\
& \bar{e}=\text { high cool sound. }
\end{aligned}
$$

${ }_{1}$ The color here was identified by the subject the same as for the word "Karl" in Marinesco's series of color plates illustrating his case. 
$\breve{\mathrm{e}}=$ no sound.

$\breve{i}=$ very high cool sound.

$\overline{\mathrm{i}}=$ no sound

Long and short $o$ and $u$, produced no sensation.

Numbers never produced colors in her, but she has always associated the cardinal numbers with a sort of visualized geometrical line arrangement, i.e.,- ascending up to ten, dropping to twenty and then gradually ascending again. The days of the week and the names of the months produced no colors. "Sunday," however, appeared "taller" than other days. All the other days of the week were of uniform height except "Saturday," which is "half as tall" as "Sunday." The seasons of the year were always peculiarly symbolized by a spiral spring, oval in shape, the ends indicating spring and autumn, the sides summer and winter. Music produced an intoxicating effect on her, but did not stimulate colors. Separate notes of the scale and the sounds of various musical instruments failed to produce colors.

Tests with the normal spectrum gave interesting results in emotional states produced by colors.

$$
\begin{aligned}
& \text { Color } \\
& \text { Purple, } \\
& \text { Blue, } \\
& \text { Green, } \\
& \text { Yellow, } \\
& \text { Red, }
\end{aligned}
$$

\section{EMOTIONAL STATES}

repulsive and depressive. not satisfied. not satisfied. flash of light. nothing.

The word "Bertha" was localized in the blue-purple end of the spectrum. No color was strong enough for "Lucy" or light enough for "Nellie."

Both hearing the words and vowels and thinking of them, produced the same sensation of color, therefore, colored thinking was present in addition to colored hearing. An interesting gustatory synesthesia was also present, but not to the extent of a genuine colored gustation. A quotation from Ruskin has always appealed to her:- "We should love beautiful colors as a child loves good things to eat." Beautiful colors have always "tasted good" to her, while color discords were nauseating and produced the effect of a blow. She expressed the condition as follows: "If I like a 
color, it leaves a delightful taste in my mouth, like the sensation when one thinks of beautiful food," or "when I put my mind intently on the colors, I taste them. I can taste blue." There was no olfactory synesthesia. Direct tests of smell and taste, proved the olfactory and gustatory sensations to be normal, but these tests did not stimulate my photisms. This taste synesthesia was less intense than the colored hearing or thinking.

An analysis of the synesthesia itself, particularly the colored hearing, gave some interesting results. The synesthesia had not varied since it was first noticed during the earliest years of childhood. It was purely a waking process and not due to unconscious associations of sounds with colors dating from the earliest years of life. This was shown by two facts, first, that in the subject's dreams, sounds have never been associated with colors, and second, because an analysis conducted in abstraction through means of free association procedures gave negative results. That the phenomenon was a cortical one, possibly physiological, is shown by the facts that neither positive nor negative after images could be produced with colors of the synesthesia, and secondly, the colors were always seen in the left half of each visual field, but not exteriorized. That genuine synesthesic hallucinations of color may be produced is shown in an observation by Lemaitre. The color was always definite, distinct and invariable, and the same sound or word was always associated with the same color. The color and sound occurred simultaneously, and instantly the sound seemed to "melt" (to use the subject's expression) into the color. A reversion of the process, thinking of the specific color, never produced the word or sound associated with that particular color. The vowels in the words designated, and not the consonants, were the instigators of the photism. Closing of the eyes did not increase the intensity of the images produced. The color was very luminous, would persist for some time after she had ceased hearing the word or thinking of it, and was not of definite shape or size, but rather like a "puddle," shading off a little at the edges.

To summarize briefly, we seem to be dealing with a limited but intense synesthesia occurring in a psycho- 
neurotic subject, but antedating the psychoneurosis by a number of years. It was probably congenital in origin and had remained unchanged since childhood. There was no heredity of familial tendency. This is of interest, as in many recorded synesthesias, the hereditary tendency has been marked, for instance, in a case of Marinesco's and in one of familial colored hearing reported by Laiquel-Lavastine. Both colored hearing and thinking were present, in which variants of blue predominated. There was also a rudimentary gustatory synesthesia.

What is the cause and origin of this interesting phenomenon, this linking of sound with color, apparently contradictory to the law of the specific energy of the senses? Under normal conditions, any form of stimulation of the retina or optic nerve, would always produce a sensation of light or color, or the stimulation of a "cold point" in the skin by a needle or a hot wire, always causes a sensation of cold. The quality of the reaction is a constant one, in spite of the variations of the stimulus used. Whether this specific invariable character of a sensation resulting from different stimuli is of peripheral or central origin, whether localized in nervous end structures or central projection fields of the cortex is a point which has not been entirely cleared up. It is probable, however, that the specificity resides as much in the end organs as in the cortex itself. A synesthesia seems to be an irradiation of the specific reactions, a phenomenon which is well known in experimental physiology.

In any case the synesthesia appears to be a cortical phenomenon, partly because of the impossiblity of producing negative or positive after images, and partly because the synesthesia was irreversible. This irreversibility of the phenomenon would also seem to prove that it was not an emotional state, but rather a physiological condition, due possibly to a physiological irradiation of impulses. The fact, too, that in my case, there were no unconscious linkings of colors with sound, and also that the photisms were instantaneous, and had not varied since they were first experienced in early childhood, would argue against the emotional explanation of the condition. This invariability of the color sensations in the synesthesia for years has also been 
noted by Dresslar in a case which was observed over a long period of time.

It seems, therefore, that we are probably dealing with an incomplete, almost congenital, differentiation of the sense of vision and the sense of hearing or rather of the cortical projection fields corresponding to the peripheral auditory and visual neurones. On account of this incomplete differentiation, a stimulus (a word heard or thought), irradiates or is derailed to a cortical center which does not correspond physiologically to the peripheral neurone stimulated. That such an irradiation of nervous impulses does occur, has been demonstrated experimentally by Sherrington and can be explained on the basis of different conduction resistances offered by different fibers, probably an over-facility of conduction at different synapses. In the clinical manifestations of apraxia, likewise, this "derailing". and irradiation of peripheral impulses is frequently seen. Thus it seems, that the theory of nerve irradiation, arising from a congenital defect of the nervous system, in which the stimualtion of one center passes over into another, varying with the individual and with the intensity of the provoked sensation, appears at present, the most satisfactory explanation of the various synesthesias.

\section{Bibliography}

C. Marinesco. - Contribution à l'Etude des Synesthesies, Journal de Psychologie Normale et Pathologique, IX, 5, 1912. (Contains colored plates of the synesthesias experienced in the subject.)

J. Downey. A Case of Colored Gustation, American Journal Psychology, October, 1911.

T. H. Raines. A Case of Psychochromesthesta, Journal Abnormal Psychology, October-November, 1909. 1908.

J. F. Harris. Colored Thinking, Journal Abnormal Psychology, June-July,

Th. Flournoy. Des Phenomenes de Synopsie (Audition Coloree), 1893.

Henrie Laures. Les Synesthesies, 1908.

F. H. Dresslar. Are Chromaesthesias Variable? I Study of an individual case, American Journal Psychology, October, 1903.

Laiquel-1 arastine. Audition Coloree Familiale, Rev. Neurol., December 15, 1901.

A. Lemaitre. Ln cas d'Audition Culoree Halluncinatorie, Arch de Psychol Vol. III. 1904. 